\title{
Large-scale variability in recruitment of the barnacle Semibalanus cariosus: its cause and effects on the population density and predator
}

\author{
Takashi Noda* \\ Laboratory of Marine Zoology, Faculty of Fisheries, Hokkaido University, 3-1-1 Minato-cho Hakodate 041-8611, Japan
}

\begin{abstract}
In marine habitats, regional hydrodynamics often cause large-scale recruitment variability of larvae. However, their resultant effects on the population and associated assemblage are poorly understood. This study was performed to examine recruitment variability of the intertidal barnacle Semibalanus cariosus at 15 sites along $90 \mathrm{~km}$ of shoreline on the Kameda Peninsula, Japan, during a 5 yr period. The cause of recruitment variability and its effects on population abundance of $S$. cariosus and the size and abundance of its predator, the whelk Nucella freycineti, were evaluated. Spatiotemporal variability in recruitment of $S$. cariosus along the Kameda Peninsula had a large temporal fluctuation with a relatively consistent spatial pattern that was likely to be determined by coastal currents, which are in turn determined by wind patterns. The resultant recruitment variability affected the population and associated assemblage at 2 spatial scales. At the local scale, i.e. within a port, barnacle recruitment variability controlled its population dynamics. At the regional scale, i.e. along tens of kilometers of coastline, the recruitment variability of the barnacle caused geographic variations in its population size and both the body size and the abundance of $N$. freycineti. These results suggest that regional oceanic current systems strongly affect the benthic assemblage at both local and regional scales by mediation of large-scale spatiotemporal variability in the recruitment of larvae.
\end{abstract}

KEY WORDS: Barnacle · Semibalanus cariosus - Recruitment variability · Larval transport · Recruitment limitation $\cdot$ Whelk $\cdot$ Nucella freycineti $\cdot$ Rocky shore

Resale or republication not permitted without written consent of the publisher

\section{INTRODUCTION}

In general, regional processes can play an important role in the local dynamics of a particular ecological system in marine habitats (e.g. Connolly \& Roughgarden 1998). In such cases, our understanding of whole system dynamics is often obscured by the differences in scale between a cause and its consequence for a particular event (Bernstein \& Goldfarb 1995). A typical example is recruitment variability in marine organisms that have planktonic larvae. As larvae can be transported far from where they are released (e.g. Shanks 1995), local populations and associated assemblages are often strongly affected by recruitment variability, which reflects the amount of external larval supply into the local population (e.g. Connell 1985, Victor 1986, Hughes 1990). On the other hand, the number of larvae will be determined by regional reproductive output and regional hydrodynamics (e.g. Rodrigues et al. 1993, Wootton 1993). As a result of these scale differences, the consequences of recruitment variability have rarely been examined at a regional scale. Consequently, our knowledge regarding the large-scale dynamics of marine ecological systems is still limited (Noda \& Nakao 1996b).

Recruitment of marine organisms can vary over several spatial scales (e.g. Caffey 1985, Raimondi 1990, Fowler et al. 1992, Noda \& Nakao 1996a, Hughes et al. 1999). Such spatial variability is likely to be the consequence of numerous processes that act at different spatial scales (e.g. Pineda 1994, Hills \& Thomason 1996). At local scales $(<100 \mathrm{~m})$, recruitment variability can be caused by settlement processes, such as microhydrodynamics or free-space availability for larvae 
(e.g. Shanks \& Wright 1987, Minchinton \& Scheibling 1993, Pineda 1994, Noda et al. 1998) and by postsettlement processes, such as predation and competition (e.g. Sutherland 1990, Osman \& Whitlatch 1995, Hunt \& Scheibling 1997). At larger scales (e.g. 10 to $100 \mathrm{~km}$ ), spatial variability in recruitment may be related to the regional larval pool (which is dependent on both number of eggs produced and larval survival) and regional physical transport processes (e.g. Hawkins \& Hartnoll 1982, Gaines \& Roughgarden 1987, Gaines \& Bertness 1992, Peterson \& Summerson 1992, Rodrigues et al. 1993, Thorrold et al. 1994, Hughes et al. 1999). Much is known about the local pattern and processes. In contrast, the effects of regional processes on spatiotemporal variability in recruitment are less well understood. Previous studies have shown that while larval recruitment variability can strongly influence the local population abundance of marine organisms, the magnitude of its influence is dependent on the strength of recruitment (e.g. Connell 1985). If the larval supply is abundant, then post-settlement processes, such as competition or predation, may be more important than recruitment variability in determining population abundance. In contrast, if larval supply is limited, then local population abundance varies as a function of the number of recruits, rather than being set by post-settlement processes (e.g. Yoshioka 1982, Underwood \& Denley 1984, Caffey 1985, Connell 1985, Gaines \& Roughgarden 1985, Levin 1986, Doherty \& Williams 1988, Mapstone \& Fowler 1988, Carroll 1996). In the latter situation, the effects of recruitment may spread to the associated assemblage (e.g. Fairweather 1988, Gaines \& Lafferty 1995, Robles et al. 1995).

The aim of the present study was to evaluate the causes and consequences of variability of recruitment in the intertidal barnacle Semibalanus cariosus along $90 \mathrm{~km}$ of coastline on the Kameda Peninsula, northern Japan to (1) determine the spatiotemporal variability of recruitment between years over a $5 \mathrm{yr}$ period at 15 shores, (2) examine the effects of recruitment variability on local population abundances of the barnacle, (3) examine the effects of recruitment variability on the size and abundance of its predator (the whelk Nucella freycineti), and (4) examine the processes responsible for the spatiotemporal recruitment variability.

\section{MATERIALS AND METHODS}

Study organisms. The barnacle Semibalanus cariosus is widely distributed along the exposed coasts of the North Pacific: from Oregon to northern Japan (Utsunomi 1965). At exposed sites in Hokkaido, this is the dominant species in sessile assemblages in the mid-intertidal zone of man-made structures (e.g. break-waters and precast concrete armor units). It matures at Age $1 \mathrm{yr}$ and can live for $5 \mathrm{yr}$ or more (pers. obs.). Adult $S$. cariosus release larvae during phytoplankton blooms (Kado 1991), which occur during March in southern Hokkaido. After 20 to 40 d, the larvae return to the intertidal habitat and settle on hard substrata (Kado 1991). Their settlement season ranges from April to June and most settlement occurs during April and May (Fukushima 1994).

On man-made structures at exposed sites, sessile animals except barnacles are rare and the predatory whelk Nucella freycineti is common. In this habitat, the whelk feeds mainly on Semibalanus cariosus and is a top predator (pers. obs.). In natural habitats (e.g. semiexposed rocky shores), the whelk is mainly distributed in beds of the black mussel Septifer virgatus; here, $S$. cariosus is rare, and the whelk feeds mainly on $S$. virgatus (Kawai 1993). This whelk lacks a planktonic larval period and can live for several years (Kawai 1993).

Study sites. This study was conducted along $90 \mathrm{~km}$ of coastline around the Kameda Peninsula (Fig. 1a). Around the Kameda Peninsula, geographic patterns in coastal currents and desiccation stress are described below.

Coastal currents: The general pattern of coastal currents during spring is characterised by 3 local areas (Fig. 1b): (1) from Cape Sunazaki to Cape Esan (distance: ca. $50 \mathrm{~km}$ ), where a southeastward flow (ca. 10 to $16 \mathrm{~km} \mathrm{~d}^{-1}$ ) is dominant (Ohtani \& Deguchi 1981, Ohtani \& Murakami 1989); (2) between Cape Esan and Cape Shiokubi (distance: ca. $20 \mathrm{~km}$ ), where a westward flow (ca. $10 \mathrm{~km} \mathrm{~d}^{-1}$ ) is dominant (Hori \& Nitta 1979); and (3) between Cape Shiokubi and Cape Tachimachi (distance: ca. $20 \mathrm{~km}$ ), where an eastward flow (ca. $10 \mathrm{~km} \mathrm{~d}^{-1}$ ) is dominant (Hori \& Nitta 1979).

Desiccation stress: While no quantitative evidence is available, the geographic pattern of the desiccation stress must be similar to the pattern of coastal currents. During the settlement period (April to June), sea fog, which weakens the direct rays of the sun, occurs frequently along the coast from Cape Sunazaki to Cape Esan, but is infrequent along the coast between Cape Shiokubi and Cape Tachimachi (pers. obs.). Consequently, the duration of sunshine is usually shorter for the Cape Sunazaki to Cape Esan coast than for the coast between Cape Shiokubi and Cape Tachimachi during the settlement season (e.g. Sapporo District Meteorological Observatory 1999). Between these 2 areas (i.e. between Cape Esan and Cape Shiokubi), while climate data have not been recorded, the fog frequency and sunshine duration may be intermediate.

Barnacle recruitment variability and its effects on adult density. Sampling: As monthly settlement monitoring on a rocky bench (Fig. 1c, Rocky bench VI) demonstrated that neither the timing of the peak nor 

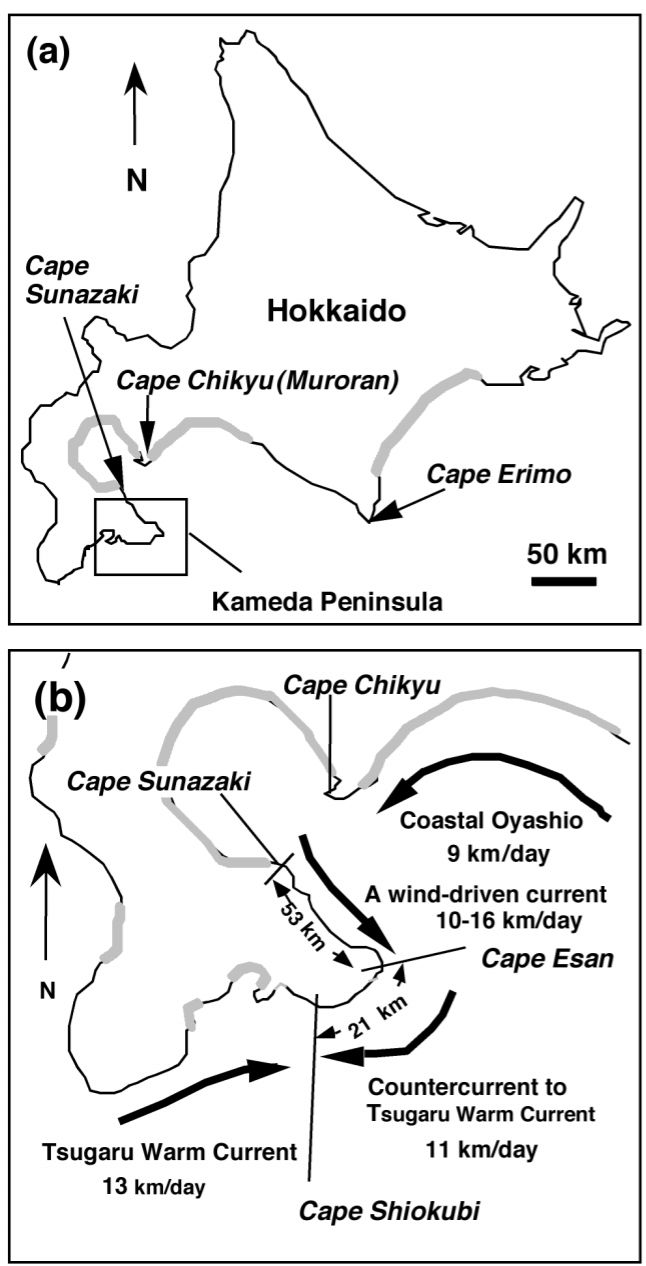

the duration of settlement changed from 1994 to 1999 (T. Noda unpubl. data), recruit sampling was conducted in early July (just after the end of the settlement season) at 15 fishing ports along the Kameda peninsula (Fig. 1c) in 1994, 1995, 1997, 1998 and 1999. On each sampling date, 15 precast concrete armor units (polyhedral concrete blocks measuring 5 to $6 \mathrm{~m}$ in width and height used to weaken wave force, hereafter designated PCAUs) separated by a distance of 1 to $2 \mathrm{~m}$ located near the end of the pier at each port were chosen at random. All PCAUs had similar microheterogeneity of substrata and were exposed to the open sea. Along the offshore side of each PCAU, a $25 \times 25 \mathrm{~cm}$ quadrat was set on the center of the Semibalanus cariosus zone locating intertidal mid-shore. Within the quadrat, a small $(5 \times 5 \mathrm{~cm})$ quadrat was set haphazardly in areas where Semibalanus adults ( $>1 \mathrm{yr}$ old) were absent. In each small quadrat, the numbers of newly settled $S$. cariosus (including empty tests) were counted. They were distinguished from adults by their color and size; the shell color of new recruits is clean white and the aperture length is $<2 \mathrm{~mm}$.

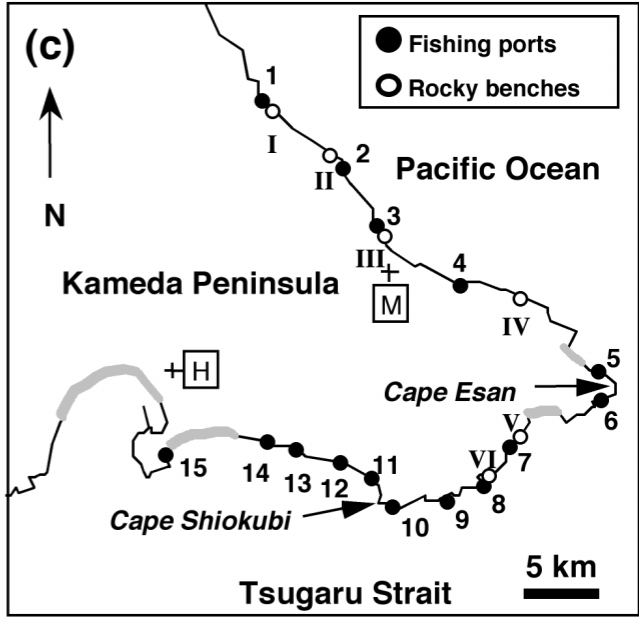

Fig. 1. Study area at the Kameda Peninsula, Japan. (a) Position of the Kameda Peninsula on Hokkaido. (b) Patterns of coastal currents around southern Hokkaido during the spring season. Arrows show coastal currents. (c) Recruitment monitoring ports on the Kameda Peninsula are numbered 1 to 15 . Rocky benches on the Kameda Peninsula are marked with Roman numerals, where shell height and density of Nucella freycineti were monitored. Solid and open circles show fishing ports and rocky benches, respectively. Two crosses indicate the locations of Automated Meteorological Data Acquisition Systems: Hakodate Automated Meteorological Data Acquisition System (H); Minamikayabe Automated Meteorological Data Acquisition System (M). Shaded areas on the coastlines indicate sandy beaches

A previous study showed that recruitment densities of Semibalanus cariosus vary at 4 spatial scales (i.e. $\mathrm{km}$ scale, among ports; 100 to $300 \mathrm{~m}$ scale, among sites within a port; 1 to $2 \mathrm{~m}$ scale, among PCAUs within sites; 5 to $20 \mathrm{~cm}$ scale, among small $5 \times 5 \mathrm{~cm}$ quadrats within a large $25 \times 25 \mathrm{~cm}$ quadrat). However, $85.6 \%$ of the total variance was estimated to be due to variation among ports (Noda \& Nakao 1996a). This result suggested that the sampling method in the present study was suitable for measurement of among-port variability of barnacle recruitment.

Densities of adult ( $>1 \mathrm{yr}$ old) Semibalanus cariosus were measured in June 1999 at 15 fishing ports (Fig. 1c). In each port, I counted the numbers of adult $S$. cariosus in a large $(25 \times 25 \mathrm{~cm})$ quadrat set using the same methods as in the recruitment sampling.

Analysis of spatiotemporal variability in recruitment: An analysis of variance was used to detect the spatiotemporal variability of recruitment of Semibalanus cariosus between 1994 and 1999 around the Kameda Peninsula, with coast (i.e. the Cape Sunazaki to Cape Esan coast, the Cape Esan to Cape Shiokubi 
coast and west of Cape Shiokubi) and year as fixed effects, and ports nested in the coast as a random effect. Effects of coast were tested over the port (coast) mean square, effects of year $\times$ coast were tested over the year $\times$ port (coast) mean square, and the effects of port (coast), year and year $\times$ port (coast) were tested over the error mean square. For the analysis, data were log transformed to make the variances homogeneous when necessary. Cochran's $C$-test was used to check for homogeneity of variances.

Test of recruitment limitation: Recruitment limitation is defined as a linear positive relation between local population abundance and the number of recruits, in which local population abundance varies as a linear function of the number of recruits because of limited larval supply (Connell 1985). To determine whether recruitment limitation occurred in the population of Semibalanus cariosus around the Kameda Peninsula, I performed linear regression analysis of the abundance of adults (individuals >0 yr of age) in 1999 against the mean recruitment density during 1994 to 1998 at each port.

Effects of spatial variability of barnacle recruitment on the Nucella freycineti population. Sampling: In June 1999, Nucella freycineti densities were measured on the Pacific coast and on the Tsugaru Strait coast around the Kameda Peninsula. Along the Pacific coast, sampling was conducted at 3 fishing ports (Fig. 1c, Ports 1, 3 and 4) and 4 adjacent black mussel (Septifer virgatus) beds (Fig. 1c, Rocky benches I, II, III and IV). On the Tsugaru Strait coast, sampling was conducted at 3 fishing ports (Fig. 1c, Ports 7, 8 and 9), 2 adjacent mussel beds (Fig. 1c, Rocky benches V and VI) and a rocky bench covered by PCAUs, where Semibalanus cariosus was dominant (Fig. 1c, Rocky bench VI).

In ports, 25 PCAUs (each separated by a distance of 1 to $2 \mathrm{~m}$ ) located near the end of the port piers were sampled. Two large $(25 \times 25 \mathrm{~cm})$ quadrats were randomly set within the Semibalanus cariosus zone of each PCAU and the whelks in the quadrats were counted. In mussel beds, a large $(25 \times 25 \mathrm{~cm})$ quadrat was randomly set 65 times in an area measuring ca. $30 \times 5 \mathrm{~m}$ located in the mid-part of each bed and the whelks were counted.

The shell heights of 50 to 149 ind. of Nucella freycineti were measured using a caliper at ports and rocky benches where their density was measured, except 1 port (Fig. 1c, Port 9) where the density was too low to collect a sufficient number of individuals for estimating distribution of the shell height. $N$. freycineti used for shell height measurement were collected from quadrats used for density measurement sampling and from the adjacent areas (i.e. $<5 \mathrm{~m}$ from each quadrat).

At each port and rocky bench, biomass $\left(\mathrm{g} 625 \mathrm{~cm}^{-2}\right)$ of Nucella freycineti was calculated from mean density and the mean individual weight, which was obtained from shell height distribution and the allometric equation log fresh weight $(\mathrm{g})=-0.60+2.82 \cdot \log$ shell height $(\mathrm{mm})\left(\mathrm{r}^{2}=0.98, \mathrm{n}=26\right.$; $\mathrm{T}$. Noda unpubl. data) obtained from specimen collected at a fishing port (Fig. 1c, Port 3).

Test of effects of barnacle recruitment variability on Nucella freycineti: The effects of barnacle recruitment variability on $N$. freycineti were evaluated along the $70 \mathrm{~km}$ of coastline from Cape Sunazaki to Cape Shiokubi. As both recruitment of Semibalanus cariosus and other confounding variables (e.g. climate factors) can vary spatially along the coastline, the confounding effects must be eliminated to evaluate the effects of barnacle recruitment variability on $N$. freycineti.

The geographic patterns of mean shell height and abundance of whelks were compared between ports where whelks feed mainly on barnacles (Fig. 1c, Ports 1 to 9) and black mussel beds where whelks feed mainly on mussels (Fig. 1c, Rocky benches I to VI). In mussel beds, the abundance of the black mussel Septifer virgatus may not be limited by larval supply but by post-settlement mortality, which determines the amount of suitable recruitment sites for larvae. This is because larvae are recruited selectively in mussel mats (Kiyoshige 1995). In contrast, the local population abundance of Semibalanus cariosus can be limited by larval supply. In comparison to geographic patterns of mean shell height and abundance of whelks between ports and black mussel beds, if similar patterns are observed for shell height and abundance between the 2 habitats, then some environmental variables but not food resources may be responsible for the observed patterns. In contrast, if a particular geographic pattern is observed only in ports and it corresponds to the barnacle recruitment pattern, then barnacle recruitment variability may be responsible for the geographic patterns of mean shell height and the abundance of whelks.

Nested ANOVAs were conducted to evaluate the spatial variability of shell height and density of Nucella freycineti at ports and on rocky benches around the Kameda Peninsula, with coast (Pacific coast vs Tsugaru Strait coast) as fixed and both ports and rocky benches nested in the coast as random effects. The effects of coast were tested over the port (coast) mean square and rocky bench (coast) mean square, while the effects of port (coast) and rocky bench (coast) were tested over the error mean square. For the analysis, data were transformed (i.e. shell height, square-root transformation; density, log transformation) to make the variances homogeneous when necessary. Cochran's $C$-test was used to check for homogeneity of variances when sample sizes were equal. In the ANOVA for rocky benches of shell height, Bartlett's test was used to check for homogeneity of variances because sample size (i.e. 
number of individuals for which shell height was measured) differed among rocky benches.

To evaluate the association between barnacle recruitment and whelk size, abundance, and biomass, linear regression analyses were conducted for the mean shell height, abundance, and biomass of the whelks in 1999 against the mean recruitment density during 1994 to 1998 at each port.

Cause of spatiotemporal recruitment pattern. Winddriven currents hypothesis: The spatiotemporal recruitment pattern of Semibalanus cariosus around the Kameda Peninsula was hypothesized to be determined mainly by coastal currents, which should transport larvae to the peninsula. There are 2 grounds for this hypothesis. First, speed and direction of coastal currents (Fig. 1b) and the larval period of S. cariosus (ca. 20 to
40 d) suggested that most larvae recruited on the Kameda Peninsula were released from the northeast of the peninsula. Second, the consistency of the geographic pattern of recruitment also supported the hypothesis, i.e. recruitment is highest on the coastline between Cape Sunazaki and Cape Esan, followed by the coastline between Cape Esan and Cape Shiokubi (Fig. 2).

To evaluate the reliability of the hypothesis that explains barnacle recruitment variability, I examined whether the observed data supported its prediction that, when NE winds are strong and NW winds are weak, overall recruitment intensity as well as the proportion of larvae recruited on the Tsugaru Strait coast would be high. This is because coastal currents around the Kameda Peninsula are dominated by wind-driven
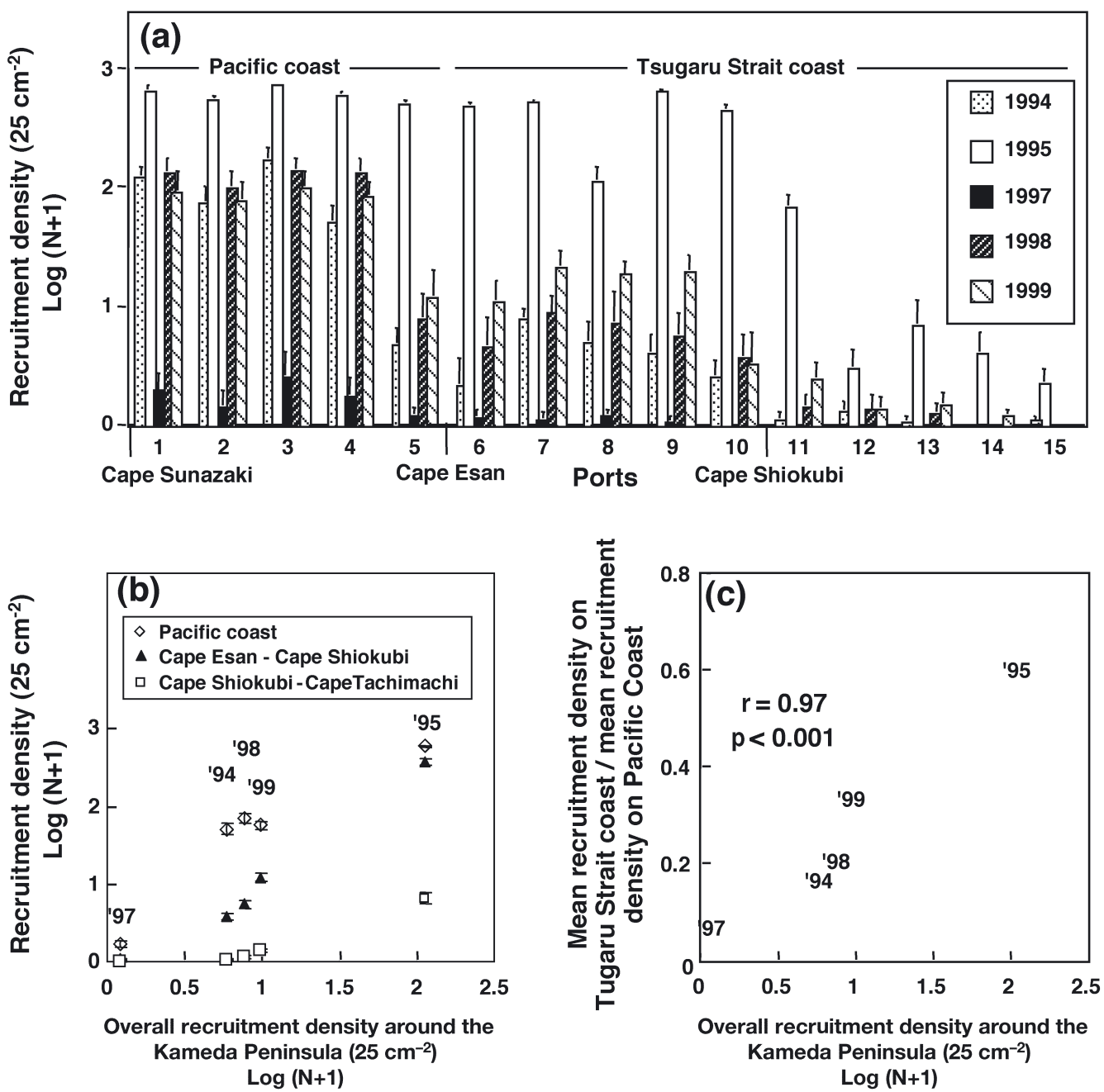

Fig. 2. Semibalanus cariosus. Recruitment variability between 1994 and 1999. (a) Spatiotemporal variability around the Kameda Peninsula. Arabic numerals indicate the ports shown in Fig. 1. (b) Relationship between the overall recruitment density around the Kameda Peninsula (i.e. mean value obtained from 15 fishing ports) and mean recruitment density at 3 coasts (i.e. the Pacific coast, the Cape Esan to Cape Shiokubi coast and the Cape Shiokubi to Cape Tachimachi coast). (c) Correlation between the overall recruitment density and the ratio of mean recruitment density on the Tsugaru Strait coast to that on the Pacific coast. Vertical 
currents (Ohtani \& Deguchi 1981, Ohtani \& Murakami 1989, Shimizu \& Isoda 1997, Isoda et al. 1998). Simulation results using a numeric model indicate that a NE wind drives a counter-clockwise current around the Kameda Peninsula (Shimizu \& Isoda 1997), while a NW wind enhances the offshore currents and prevents flows from reaching the Kameda Peninsula (Isoda et al. 1998).

The NE and NW scalars of the resultant winds in 1994, 1995, 1997, 1998 and 1999 were obtained as follows. In each year, daily mean wind force and daily most frequent wind direction during March to May were obtained from the Automated Meteorological Data Acquisition System (AMDAS) at Cape Chikyu. From these data, the resultant winds during March, April and May in each year were obtained, and the NE and NW scalars of the resultant winds were calculated. Then, correlations were obtained (1) between the yearly mean of recruitment of Semibalanus cariosus and the NE and NW scalars of resultant wind velocity, and (2) between the ratio of mean recruitment density on the Tsugaru Strait coast to that on the Pacific coast and NE and NW scalars of the resultant wind velocity.

Desiccation hypothesis: An alternative hypothesis is that spatiotemporal variability in desiccation stress resulted in differences in early post-settlement mortality, consequently giving rise to the spatiotemporal recruitment pattern of Semibalanus cariosus around the Kameda Peninsula. This hypothesis was evaluated by using (1) the sunshine durations during April to June (as an indicator of strength of desiccation stress for early post-settlement barnacles), which were obtained from AMDAS at Hakodate and Minamikayabe (Fig. 1c) and (2) the annual mean density of recruits observed in ports 3 and 15 which are nearest to the AMDAS at Hakodate and Minamikayabe, respectively. The effect of sunshine duration on annual barnacle recruitment at the 2 ports was evaluated by selecting the best subset of predictors in a multiple regression with 2 predictor variables, i.e. 'the sunshine duration during April to June' and 'ports', and their interaction. 'Ports' was treated as a categorical predictor variable, since some factors (e.g. larval supply) as well as sunshine duration might affect recruitment. I determined the best subset of predictors based on the Akaike Information Criterion (AIC) and adjusted $\mathrm{R}^{2}$, i.e. the best-fit model has the smallest AIC and the largest adjusted $\mathrm{R}^{2}$ (Quinn \& Keough 2002). If the best subset of predictors contained neither sunshine duration effects nor an interaction between sunshine duration and port in the regression, then this desiccation stress hypothesis could not be supported. In this analysis, the annual mean recruitment densities were log transformed because the mortality may respond to strength of desiccation stress non-linearly rather than linearly.

\section{RESULTS}

\section{Barnacle recruitment variability}

During the study period, Semibalanus cariosus recruitment showed a relatively consistent spatial pattern, while recruitment densities fluctuated from year to year (Fig. 2a, Table 1). In all years, the recruitment level was highest on the Cape Sunazaki to Cape Esan coast, followed by the Cape Esan to Cape Shiokubi coast. While temporal trends in recruitment variability is also similar among the 3 coastlines, the spatial pattern of recruitment changed with the overall recruitment intensity around the Kameda Peninsula (Fig. 2b). The differences in recruitment density between the Cape Sunazaki to Cape Esan coast and the Cape Esan

Table 1. Semibalanus cariosus. ANOVA for the spatiotemporal variability of recruitment between 1994 and 1999 around the Kameda Peninsula, with coast and year as fixed, and ports nested in the coast as random effects

\begin{tabular}{|lrrrr|}
\hline Source of variation & df & \multicolumn{1}{c}{ MS } & $F$ & $p$ \\
\hline Coast $^{\text {a }}$ & 2 & 197.71 & 50.11 & $<0.0001$ \\
Port(Coast) & 12 & 3.95 & 62.18 & $<0.0001$ \\
Year & 4 & 112.19 & 1768.09 & $<0.0001$ \\
Year $\times$ Coast & 8 & 13.77 & 15.26 & $<0.0001$ \\
Year $\times$ Port(Coast) & 48 & 0.90 & 14.22 & $<0.0001$ \\
Error & 1050 & 0.06 & & \\
Transformation: $\log (\mathrm{N} \cdot 1000+1)$ & & \\
Cochran's C-test: C $=0.056$, p $>0.05$ & & \\
a Coast: the Cape Sunazaki to Cape Esan coast, the Cape \\
Esan to Cape Shiokubi coast and west of Cape Shiokubi \\
\hline
\end{tabular}

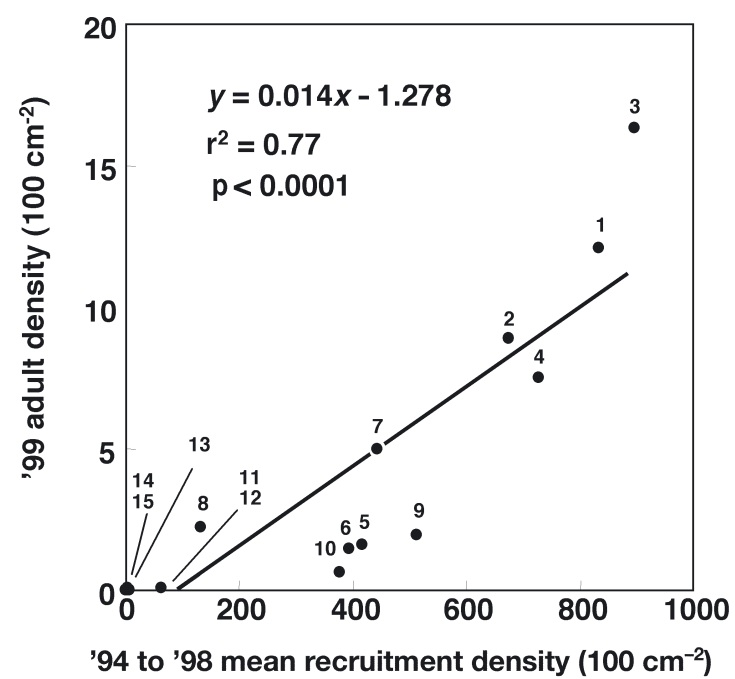

Fig. 3. Semibalanus cariosus. Regression analysis of the adult density in 1999 against mean recruitment density during 1994 to 1998. Arabic numerals indicate the ports shown in Fig. 1c 
to Cape Shiokubi coast decreased with increasing overall recruitment intensity around the peninsula. In addition, the ratio of mean recruitment density on the Tsugaru Strait coast to that on the Pacific coast was positively correlated to the overall recruitment intensity around the peninsula (Fig. 2c).

\section{Effects of barnacle recruitment variability on its population abundance}

The result of linear regression analysis of adult density in 1999 against the recruitment intensity (i.e. the mean recruitment density during 1994 to 1998) was highly significant (Fig. 3). These results suggest that the barnacle population abundance varied among ports as a linear function of the number of recruits.

\section{Spatial variability in growth and abundance of Nucella freycineti}

In ports and on rocky benches where whelks fed mainly on Semibalanus cariosus, the shell size of the whelks was larger on the Pacific coast than on the Tsugaru Strait coast, while in mussel beds, no such pattern was observed (Fig. 4, Table 2). Shell size of whelks in the $S$. cariosus zone on a natural rocky bench was similar to that at the adjacent fishing port (Fig. 4, comparing Site VI with Site 8). At ports, the densities of whelks were higher on the Pacific coast than on the Tsugaru Strait coast. In mussel beds, no such pattern was observed (Fig. 5, Table 3).

Significant linear regressions were obtained for density, shell height and biomass of Nucella freycineti against the mean recruitment density of Semibalanus cariosus (Fig. 6).

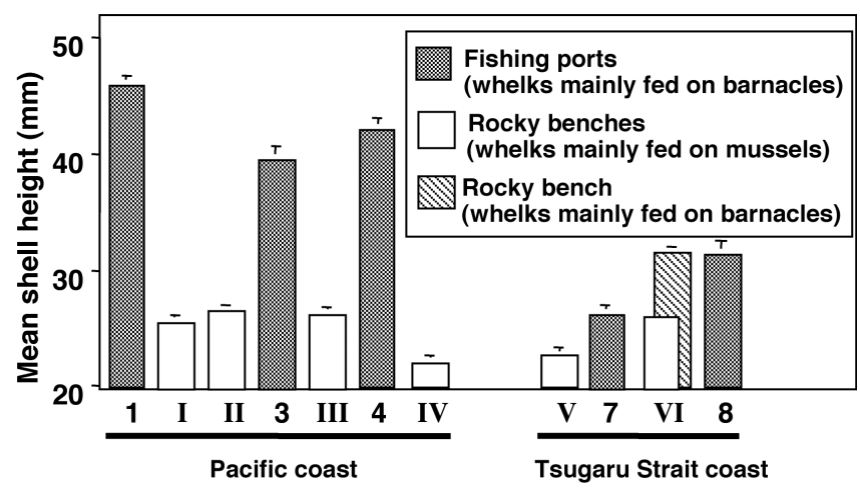

Fig. 4. Nucella freycineti. Spatial variability in mean shell height around the Kameda Peninsula. Vertical bars are SE. On the $x$-axis, Arabic and Roman numerals refer to the ports and rocky benches in Fig. 1c, respectively

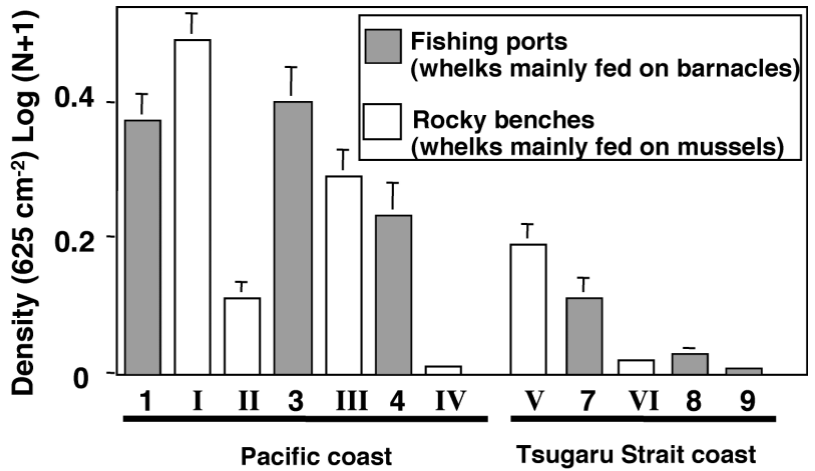

Fig. 5. Nucella freycineti. Spatial variability in density around the Kameda Peninsula. Vertical bars are SE. On the $x$-axis, Arabic and Roman numerals refer to the ports and rocky benches shown in Fig. 1c, respectively

\section{Conformity between observations and hypothesis predictions regarding the cause of recruitment variation}

The yearly mean of recruitment density of Semibalanus cariosus along the Kameda Peninsula and the ratio of mean recruitment density on the Tsugaru Strait coast to that of the Pacific coast were positively correlated to the NE scalar (Fig. 7a,b), and negatively correlated to the NW scalar (Fig. $7 \mathrm{c}, \mathrm{d}$ ). These observations were consistent with the prediction that coastal currents mainly determined the recruitment pattern of $S$. cariosus around the Kameda Peninsula.

The recruitment density was lower and the hours of sunshine duration during April to June were higher at Port 3, located on the Pacific coast than at Port 15,

Table 2. Nucella freycineti. Nested ANOVA of shell height around the Kameda Peninsula, with coast as fixed and both ports and rocky benches nested in coast as random effects.

(a) Ports (b) Rocky benches

\begin{tabular}{|c|c|c|c|c|}
\hline Source of variation & df & MS & $F$ & $\mathrm{p}$ \\
\hline \multicolumn{5}{|l|}{ (a) Ports } \\
\hline Coast $^{a}$ & 1 & 63.870 & 53.790 & 0.005 \\
\hline Port(Coast) & 3 & 1.187 & 2.951 & 0.033 \\
\hline Error & 245 & 0.402 & & \\
\hline \multicolumn{5}{|l|}{ Transformation: none } \\
\hline \multicolumn{5}{|c|}{ Cochran's $C$-test: $C=0.274, \mathrm{p}>0.05$} \\
\hline \multicolumn{5}{|l|}{ (b) Rocky benches } \\
\hline Coast & 1 & 0.502 & 0.206 & 0.673 \\
\hline Rocky bench(Coast) & 4 & 2.434 & 9.707 & 0.000 \\
\hline Error & 362 & 0.251 & & \\
\hline \multicolumn{5}{|c|}{ Transformation: square root } \\
\hline \multicolumn{5}{|c|}{ Bartlett's test: $B=9.220, p>0.05$} \\
\hline \multicolumn{5}{|c|}{${ }^{\mathrm{a}}$ Coast: Pacific coast vs Tsugaru Strait coast } \\
\hline
\end{tabular}


Table 3. Nucella freycineti. Nested ANOVA of density around the Kameda Peninsula, with coast as fixed and both ports and rocky benches nested in coast as random effects. (a) Ports (b) Rocky benches

\begin{tabular}{|c|c|c|c|c|}
\hline Source of variation & df & MS & $F$ & $\mathrm{p}$ \\
\hline \multicolumn{5}{|l|}{ (a) Ports } \\
\hline Coast $^{a}$ & 1 & 168.2 & 14.20 & 0.020 \\
\hline Port(Coast) & 4 & 11.6 & 6.06 & 0.0001 \\
\hline Error & 294 & 1.9 & & \\
\hline \multicolumn{5}{|c|}{ Cochran's $C$-test: $C=0.284, \mathrm{p}>0.05$} \\
\hline \multicolumn{5}{|l|}{ (b) Rocky benches } \\
\hline Coast & 1 & 34.4 & 0.44 & 0.542 \\
\hline Rocky bench(Coast) & 4 & 77.6 & 45.30 & 0.0001 \\
\hline Error & 384 & 1.7 & & \\
\hline \multicolumn{2}{|c|}{ Transformation: $\log (\mathrm{N} \cdot 1000+1)$} & \multicolumn{3}{|c|}{ Cochran's $C$-test: $C=0.242, \mathrm{p}>0.05$} \\
\hline${ }^{a}$ Coast: Pacific coast & vs Ts & $\mathrm{ru} \mathrm{St}$ & & \\
\hline
\end{tabular}

Table 4. Semibalanus cariosus. The effect of sunshine duration on annual recruitment at the 2 ports evaluated by selecting the best subset of predictors in a multiple regression $(\mathrm{n}=10)$ with 2 predictor variables, i.e. 'the sunshine duration during April to June' and 'ports' and their interaction (Port $\times$ Sunshine duration). The best subset of predictors had the smallest Akaike Information Criterion (AIC) and adjusted $\mathrm{R}^{2}$. Significant predictor variables: ${ }^{*} 0.01 \leq \mathrm{p}<0.05 ;{ }^{* *} 0.001 \leq$ $\mathrm{p}<0.01$

\begin{tabular}{|lcccc|}
\hline $\begin{array}{l}\text { No. pre- } \\
\text { dictors }\end{array}$ & Predictor variables & $\mathrm{R}^{2}$ & $\begin{array}{c}\text { Adjusted } \\
\mathrm{R}^{2}\end{array}$ & AIC \\
\hline 3 & $\begin{array}{c}\text { Port } \\
\text { Sunshine duration } \\
\end{array}$ & 0.719 & 0.578 & -2.954 \\
2 & $\begin{array}{c}\text { Port } \times \text { Sunshine duration } \\
\text { Port* }\end{array}$ & 0.718 & 0.638 & -4.939 \\
1 & Sunshine duration & & & \\
1 & Port** & 0.713 & 0.667 & -6.765 \\
& Sunshine duration & 0.393 & 0.317 & 0.734 \\
\hline
\end{tabular}

located on the Tsugaru Strait coast (Fig. 8). However, when the sunshine duration during April to June was of similar levels in both ports (1994 and 1999 for Port 3 vs 1995, 1997 and 1998 for Port 15), the recruitment density at Port 3 was much higher than at Port 15 . Moreover, neither sunshine duration effects nor sunshine duration $\times$ port interaction effects was included in the best subset of predictors in multiple regression explaining the recruitment variability at the 2 ports (Table 4). These findings suggested that desiccation stress did not cause the spatiotemporal recruitment pattern of Semibalanus cariosus around the Kameda Peninsula via differences in early post-settlement mortality.

\section{DISCUSSION}

\section{Recruitment variability and its cause}

Spatiotemporal variability in recruitment of Semibalanus cariosus along the $90 \mathrm{~km}$ of the Kameda Peninsula could be characterized as exhibiting large temporal fluctuations but with a relatively consistent spatial pattern. Similar patterns in recruitment have been observed for barnacles and other marine benthos at similar spatial scales (e.g. Caffey 1985, Connell 1985, Tolimieri et al. 1998). In addition, recent studies have documented that these patterns are related to the rate of larval supply, which reflects oceanographic transport processes (e.g. Bertness et al. 1996). The correlations between the wind vectors and recruitment patterns are consistent with the hypothesis that the
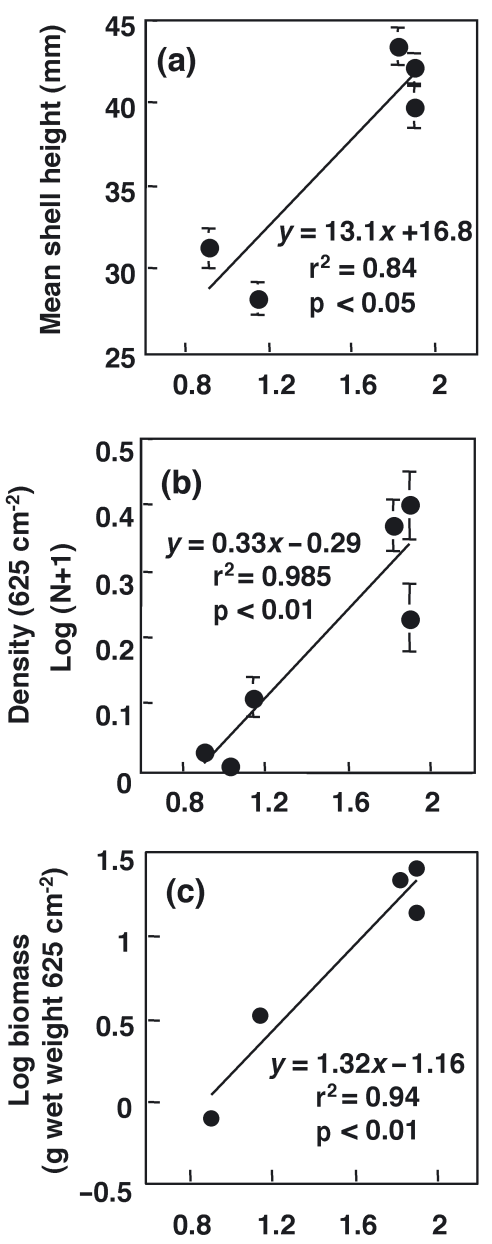

'94 to '98 mean recruitment density $\left(25 \mathrm{~cm}^{-2}\right) \log (\mathrm{N}+1)$

Fig. 6. Nucella freycineti and Semibalanus cariosus. Regression analysis of (a) mean shell height, (b) density and (c) biomass of $N$. freycineti in the ports against mean recruitment density of S. cariosus during 1994 to 1998 . Vertical bars are SE 

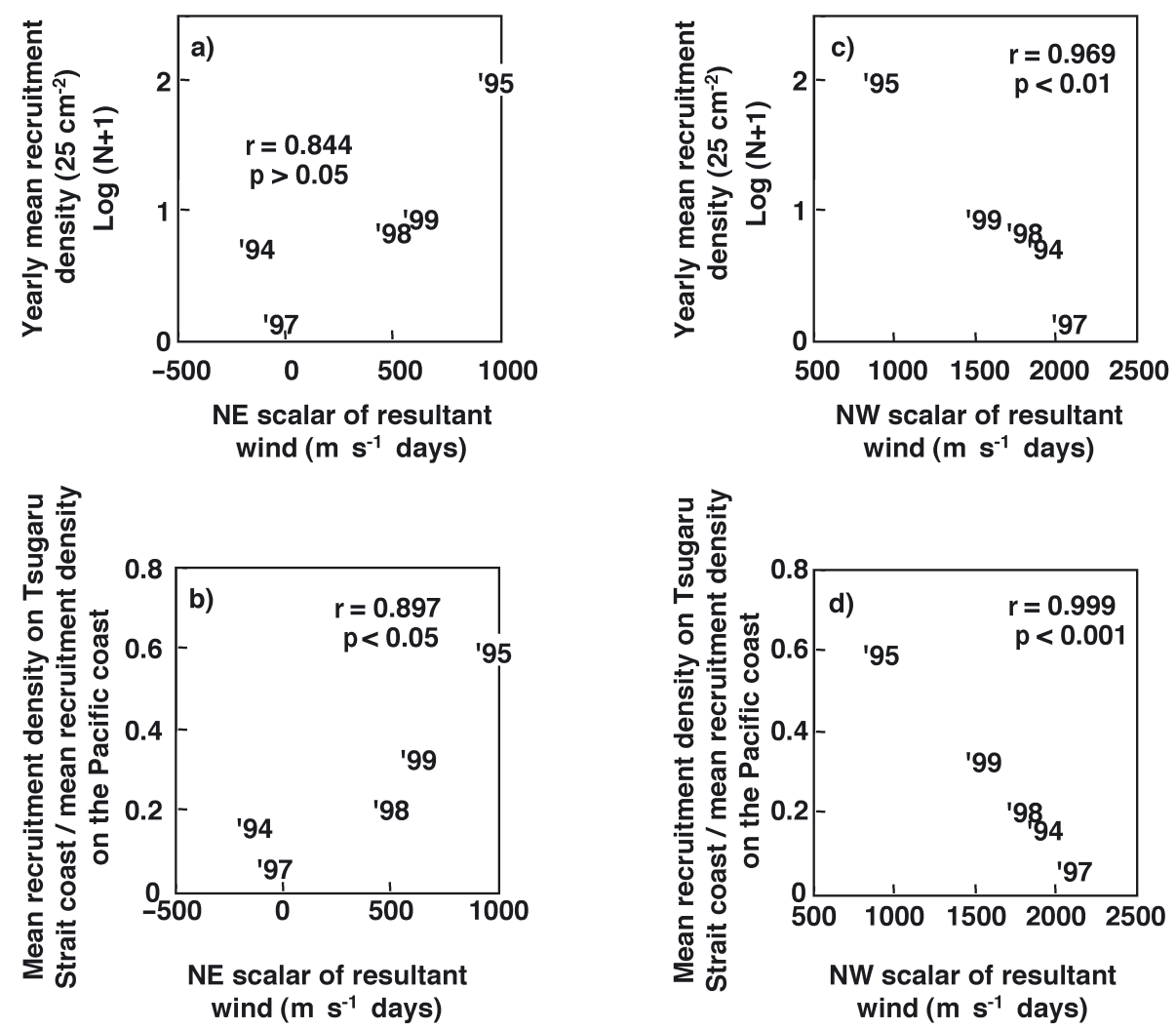

Fig. 7. Semibalanus cariosus. Correlations between barnacle recruitment and wind pattern. (a) Correlation between yearly mean recruitment density and NE scalar of resultant wind velocity at Muroran during March and May. (b) Correlation between the ratio of mean recruitment density on the Tsugaru Strait coast to that on the Pacific coast and NE scalar of resultant wind velocity at Muroran during March and May. (c) Correlation between yearly mean recruitment density and NW scalar of resultant wind velocity at Muroran during March and May. (d) Correlation between the ratio of mean recruitment density on the Tsugaru Strait coast to that on the Pacific coast and NW scalar of resultant wind velocity at Muroran during March and May

spatiotemporal recruitment patterns of $S$. cariosus around the Kameda Peninsula were determined by coastal currents, which transported larvae released from NE of the peninsula. This hypothesis was based on the speed and direction of the coastal current, the larval period of $S$. cariosus and the consistent geographic pattern of recruitment (Fig. 7). An alternative explanation is that early post-settlement mortality varies geographically and causes the pattern. The results of a previous study, however, suggested that this is unlikely (Noda \& Nakao 1996a). Recruitment densities of $S$. cariosus varied at 4 spatial scales (i.e. $\mathrm{km}$ scale, 100 to $300 \mathrm{~m}$ scale, 1 to $2 \mathrm{~m}$ scale, 5 to $20 \mathrm{~cm}$ scale) among and within the ports. $85.6 \%$ of the total variance was estimated to be due to variation among ports (Noda \& Nakao 1996a). The variance component pattern is unlikely to be the result of post-settlement mortality, which has various causes (e.g. predation, environmental stress) acting at different spatial scales (e.g. Caffey 1985). Moreover, the post-settlement mortality of intertidal sessile organisms usually varies

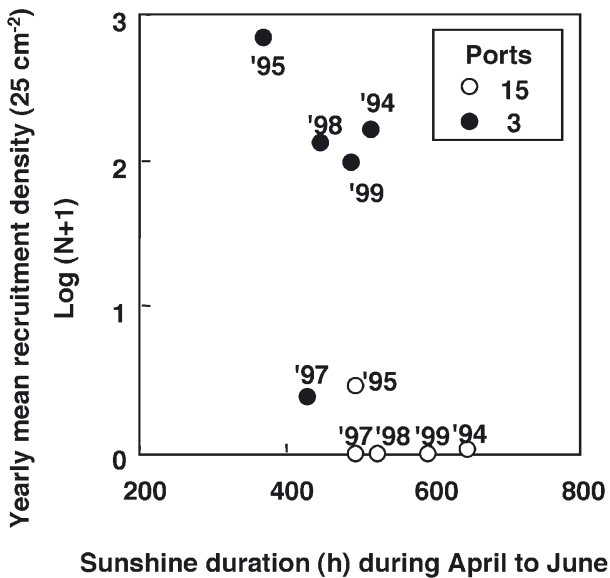

Fig. 8. Semibalanus cariosus. Relationship between the duration of sunshine during April to June, determined from 2 Automated Meteorological Data Acquisition Systems located at the Pacific and the Tsugaru Strait coasts, and annual mean density of recruits observed in 2 ports adjacent to the Automated Meteorological Data Acquisition Systems. Numbers refer to the ports shown in Fig. 1c 
highly at very small spatial scales, such as several tens of centimeters to several meters (e.g. Menge 1978a, 1978b, Caffey 1985).

These observations raise questions regarding the primary cause of the spatiotemporal variability of recruitment of Semibalanus cariosus along the 90-km Kameda Peninsula. The recruitment variability is strongly related to the coastal current pattern, which is determined by wind patterns at the regional scale. The wind pattern was strongly affected by the course of low pressure fronts (Sapporo District Meteorological Observatory 1974), which reflect the course and strength of the prevailing westerlies, which are determined by global climate (Holton 1979). Thus, year-toyear variability in the global climate may be the primary cause of the temporal variability of recruitment of $S$. cariosus along the $90 \mathrm{~km}$ of the Kameda Peninsula.

\section{Consequence of recruitment variability}

Among ports, variation in the density of adult Semibalanus cariosus around the Kameda Peninsula could be explained by a linear function of the recruitment strength at each port (Fig. 3). This suggests that recruitment limitation occurred at ports throughout the Kameda Peninsula; the local population abundance was set by the number of recruits, rather than by postsettlement processes (Connell 1985). This suggests that recruitment density was too low for densitydependent mortality to operate effectively after settlement (Connell 1985, Menge 2000).

Prey availability often affects predator body size and density in the intertidal habitat (e.g. Morgan 1972, Menge et al. 1994). Thus, it is not surprising that prey recruitment variability affects the population characteristics of the predator. Fairweather (1988) demonstrated that prey recruitment can affect whelk density on a small spatial scale by manipulation of the number of recruits. While manipulation is the most direct test of the effect of variation in prey recruitment on their predator (Fairweather 1988), this can be difficult to do, especially on a relatively large spatiotemporal scale. At the large spatial scale, alternatively, spatial correlation between recruitment intensity of prey and both size and density of the predator may be an informative evidence of bottom-up control of the consumer by prey recruitment. However, the observed correlation should be interpreted cautiously. Spatial variation in both size structure and density of predator might be caused by other confounding variables (e.g. physical factors) that vary spatially; the abundance and size of whelks can vary with exposure to waves and desiccation stress (e.g. Menge 1978a,b, Moran 1985).
Spatial variations in both the size structure and density of Nucella freycineti in ports around the Kameda Peninsula are likely to be caused by variability in prey recruitment. Several observations support this hypothesis. First, the body size and abundance of $N$. freycineti were positively correlated with the recruitment intensity of Semibalanus cariosus. Second, at ports, shell size and abundance of the whelks were larger on the Pacific coast than on the Tsugaru Strait coast, while a different spatial pattern was observed in mussel beds (Fig. 5, Table 2). Third, there was no evidence of an effective predator of whelks in this habitat; during the study period, no predation on whelks was observed and all whelks measured had a complete shell ridge (i.e. there were no signs of crab attack) (T. Noda unpubl. data). Moreover, the physical environment (e.g. temperature, desiccation stress and wave exposure) could not explain the spatial patterns in body size and abundance of the whelks. Geographic patterns in sunshine duration suggest that desiccation stress was strongest on the Cape Shiokubi to Cape Tachimachi coast and weakest on the Cape Sunazaki to Cape Esan coast (Sapporo District Meteorological Observatory 1999). However, it did not seem to affect $N$. freycineti on PCAUs, as the complex structure of PCAUs prevents direct sunlight reaching the substrata. Moreover, strong wave exposure keeps the $S$. cariosus zone wet in the habitats all year round (pers. obs.). There were no obvious spatial patterns in wave exposure (e.g. Japan Meteorological Agency 2001). In addition, there were no obvious differences in seawater temperature between the Pacific coast and the Tsugaru Strait coast from Cape Esan and Cape Shiokubi. Monthly temperature measurement conducted on 5 rocky benches (3 shores from Cape Sunazaki to Cape Esan; 2 shores between Cape Esan and Cape Shiokubi) from 1997 to 1999 showed that annual mean temperature was 8 to $9^{\circ} \mathrm{C}$ on all shores (T. Noda unpubl. data).

\section{CONCLUSIONS}

As in other large-scale studies, the present study did not evaluate the effect of all the local factors affecting recruitment (e.g. variability in chemical, physical and biological cues), implying that their effects may not be negligible. However, the present study suggested that regional climate and oceanic currents strongly affect spatiotemporal variability of Semibalanus recruitment along the $90-\mathrm{km}$ coastline of the Kameda Peninsula. The resultant variability in recruitment affected the population and associated assemblages at 2 spatial scales. At the local scale, i.e. within a port, recruitment variability seemed to control barnacle population dynamics. At the regional scale, i.e. along the $90 \mathrm{~km}$ of 
coastline, this recruitment variability caused geographic variations in barnacle population size and both body size and population size of Nucella freycineti. Previous studies on rocky intertidal shores suggest that the regional oceanic current systems often determine the large-scale variability in recruitment of benthos (Hawkins \& Hartnoll 1982, Wing et al. 1995, Connolly et al. 2001). The resultant recruitment variability often causes temporal variability in local predator abundance through bottom-up effects (Menge et al. 1994, 1999, Robles et al. 1995, Connolly et al. 2001). The results of these previous studies and observations reported here imply that the global climate and regional oceanic current systems strongly affect the benthic assemblage at local and regional scales, by mediating large-scale spatiotemporal variability in recruitment of larvae (e.g. Roughgarden et al. 1988, Alexander \& Roughgarden 1996, Connolly \& Roughgarden 1998).

Acknowledgements. I am grateful to C. Noda, T. Takase and N. Miyashita for their field assistance. I would also like to thank Y. Miyamoto and A. Ilano for their constructive comments on the manuscript. Y. Isoda made valuable suggestions concerning coastal currents and wind. T. Kobayashi and K. Wakahara of Hakodate Marine Observatory provided valuable meteorological information. This study was supported in part by a Grant-in-Aid for Scientific Research (No. 09740572) from the Ministry of Education, Science, Sports and Culture of Japan.

\section{LITERATURE CITED}

Alexander SE, Roughgarden J (1996) Larval transport and population dynamics intertidal barnacles: a couples benthic/oceanic model. Ecol Monogr 66:259-275

Bernstein BB, Goldfarb L (1995) A conceptual tool for generating and evaluating ecological hypotheses. BioScience 45:32-39

Bertness MD, Gaines SD, Wahle RA (1996) Wind-driven settlement patterns in the acorn barnacle Semibalanus balanoides. Mar Ecol Prog Ser 137:103-110

Caffey HM (1985) Spatial and temporal variation in settlement and recruitment on intertidal barnacles. Ecol Monogr 55:313-332

Carroll ML (1996) Barnacle population dynamics and recruitment regulation in southcentral Alaska. J Exp Mar Biol Ecol 199:285-302

Connell JH (1985) The consequences of variation in initial settlement vs post-settlement mortality in rocky intertidal communities. J Exp Mar Biol Ecol 93:11-45

Connolly SR, Roughgarden J (1998) A latitudinal gradient in northeast Pacific intertidal community structure: evidence for an oceanographically based synthesis of marine community theory. Am Nat 151:311-326

Connolly SR, Menge BA, Roughgarden J (2001) A latitudinal gradient in recruitment of intertidal invertebrates in the northeast Pacific Ocean. Ecology 82:1799-1813

Doherty PJ, Williams DM (1988) The replenishment of coral reef fish populations. Oceanogr Mar Biol Annu Rev 26: $487-551$
Fairweather PG (1988) Consequences of supply-side ecology: manipulating the recruitment of intertidal barnacles affects the intensity of predation upon them. Biol Bull 175: 349-354

Fowler AJ, Doherty PJ, Williams DMcB (1992) Multi-scale analysis of recruitment of a coral reef fish on the Great Barrier Reef. Mar Ecol Prog Ser 82:131-141

Fukushima K (1994) Recruitment Processes of Barnacle Semibalanus cariosus at Usujiri, Hokkaido. MS thesis, Hokkaido University, Hakodate

Gaines S, Bertness MD (1992) Dispersal of juveniles and variable recruitment in sessile marine species. Nature 360: $579-580$

Gaines S, Lafferty KD (1995) Modeling the dynamics of marine species: the importance of incorporating larval dispersal. In: McEdward LR (ed) Marine invertebrate larvae. CRC Press, Boca Raton, p 389-412

Gaines S, Roughgarden J (1985) Larval settlement rate: a leading determinant of structure in an ecological community of the marine intertidal zone. Proc Natl Acad Sci USA 82:3707-3711

Gaines S, Roughgarden J (1987) Fish in offshore kelp forests affect recruitment to intertidal barnacle populations. Science 235:479-481

Hawkins SJ, Hartnoll RG (1982) Settlement patterns of Semibalanus balanoides (L.) in the Isle of Man (1977-1981). J Exp Mar Biol Ecol 62:271-283

Hills JM, Thomason JC (1996) A multi-scale analysis of settlement density and pattern dynamics of the barnacle Semibalanus balanoides. Mar Ecol Prog Ser 138:103-115

Holton JR (1979) An introduction to dynamic meteorology. Academic Press, New York

Hori S, Nitta K (1979) Mechanism of water flow dynamics in Tsugaru Strait. In: Hori S, Nitta K (eds) General scientific reports about Tsugaru Warm Current. Research Coordination Bureau, Tokyo, p 14-55

Hughes TP (1990) Recruitment limitation, mortality, and population regulation in open systems: a case study. Ecology 71:12-20

Hughes TP, Baird AH, Dinsdale EA, Moltschaniwskyj NA, Pratchett MS, Tanner JE, Willis BL (1999) Patterns of recruitment and abundance of corals along the Great Barrier Reef. Nature 397:59-62

Hunt HL, Scheibling RE (1997) Role of early post-settlement mortality in recruitment of benthic marine invertebrates. Mar Ecol Prog Ser 155:269-301

Isoda Y, Shimizu M, Ueoka A, Matsuo Y, Ohtani K, Nakatani $\mathrm{T}$ (1998) Interannual variations of oceanic conditions related to the walleye pollock population around the Pacific Sea area, south of Hokkaido. Bull Jpn Soc Fish Oceanogr 62:1-11

Japan Meteorological Agency (2001) Annual report on ocean waves. Japan Meteorological Agency, Tokyo

Kado R (1991) Dynamics of Semibalanus cariosus from larval release to settlement. Kaiyo 23:630-634

Kawai K (1993) Bioenergetics of a Nucella freycineti population. $\mathrm{PhD}$ thesis, Hokkaido University, Hakodate

Kiyoshige S (1995) Recruitment pattern and population dynamics of black mussel Septifer virgatus (Wiegmann). MS thesis, Hokkaido University, Hakodate

Levin R (1986) Supply side ecology. Science 234:25-27

Mapstone BD, Fowler AJ (1988) Recruitment and structure of assemblages of fish on coral reefs. Trends Ecol Evol 3: $72-77$

Menge BA (1978a) Predation intensity in a rocky intertidal community: relation between predator foraging activity and environmental harshness. Oecologia 34:1-16 
Menge BA (1978b) Predation intensity in a rocky intertidal community: effect of an algal canopy, wave-action, and desiccation on predator feeding rates. Oecologia 34:17-35

Menge BA (2000) Recruitment vs. postrecruitment processes as determinants of barnacle population abundance. Ecol Monogr 70:265-288

Menge BA, Berlow EL, Blanchette CA, Navarrete SA, Yamada SB (1994) The keystone species concept: variation in interaction strength in a rocky intertidal habitat. Ecol Monogr 64:249-286

Menge BA, Daley BA, Lubchenco J, Sanford E, Dahlhoff E, Halpin PM, Hudson G, Burnaford JL (1999) Top-down and bottom-up regulation of New Zealand rocky intertidal communities. Ecol Monogr 69:297-330

Minchinton TE, Scheibling RE (1993) Free space availability and larval substratum selection as determinants of barnacle population structure in a developing rocky intertidal community. Mar Ecol Prog Ser 95:233-244

Moran MJ (1985) Distribution and dispersion of the predatory intertidal gastropod Morula marginalba. Mar Ecol Prog Ser 22:41-52

Morgan PR (1972) The influence of prey availability on the distribution and predatory behavior of Nucella lapillus (L.). J Anim Ecol 41:257-274

Noda T, Nakao S (1996a) Multi-scale spatial patterns of recruitment in the barnacles Semibalanus cariosus at fishing ports on the Kameda Peninsula, southern Hokkaido, Japan. Hydrobiologia 324:125-130

Noda T, Nakao S (1996b) Dynamics of an entire population of the subtidal snail Umbonium costatum: the importance of annual recruitment fluctuation. J Anim Ecol 65:196-204

Noda T, Fukushima K, Mori T (1998) Daily settlement variability of the barnacle Semibalanus cariosus: importance of physical factors and density-dependent processes. Mar Ecol Prog Ser 169:289-293

Ohtani K, Deguchi R (1981) Coastal upwelling off the eastern coast of the Oshima Peninsula-1. Bull Fac Fish Hokkaido Univ 32:77-96

Ohtani K, Murakami T (1989) Statistics on wind-induced coastal currents along the east coast of the Oshima Peninsula. Bull Fac Fish Hokkaido Univ 40:30-49

Osman RW, Whitlatch RB (1995) Predation on early ontogenetic life stages and its effect on recruitment into a marine epifaunal community. Mar Ecol Prog Ser 177:111-126

Peterson CH, Summerson HC (1992) Basin-scale coherence of population dynamics of an exploited marine invertebrate, the bay scallop: implications of recruitment limitation. Mar Ecol Prog Ser 90:257-272

Pineda J (1994) Spatial and temporal patterns in barnacle settlement rate along a southern California rocky shore. Mar Ecol Prog Ser 107:125-138

Quinn GP, Keough MJ (2002) Experimental design and data analysis for biologists. Cambridge University Press, Cambridge

Raimondi PT (1990) Patterns, mechanisms, consequences of variability in settlement and recruitment of an intertidal

Editorial responsibility: Otto Kinne (Editor),

Oldendorf/Luhe, Germany barnacle. Ecol Monogr 60:283-309

Robles C, Sherwood-Stephens R, Alvarado M (1995) Responses of a key intertidal predator to varying recruitment of its prey. Ecology 76:565-579

Rodrigues SR, Ojeda FP, Inestrosa NC (1993) Settlement of benthic marine invertebrates. Mar Ecol Prog Ser 97: 193-207

Roughgarden J, Gaines S, Possingham H (1988) Recruitment dynamics in complex life cycles. Science 241:1460-1466

Sapporo District Meteorological Observatory (1974) Hokkaido chihou kisho kaisetu shiryou: kaze. Sapporo District Meteorological Observatory, Sapporo

Sapporo District Meteorological Observatory (1999) Hokkaido Kisho Geppou, July-August. Sapporo District Meteorological Observatory, Sapporo

Shanks AL (1995) Mechanisms of cross-shelf dispersal of larval invertebrates and fish. In: McEdward LR (ed) Marine invertebrate larvae. CRC Press, Boca Raton, p 323-367

Shanks AL, Wright WG (1987) Internal-wave mediated shoreward transport of cyprid, megalopae, and gammarids and correlated longshore differences in the settling rate of intertidal barnacles. J Exp Mar Biol Ecol 144:1-13

Shimizu S, Isoda Y (1997) The transport process of walleye pollock eggs into Funka Bay in winter. Bull Jpn Soc Fish Oceanogr 61:134-143

Sutherland JP (1990) Recruitment regulates demographic variation in a tropical intertidal barnacle. Ecology 71: 955-972

Thorrold SR, Shenker JM, Mojica R Jr, Maddox ED, Wishinski E (1994) Temporal patterns in the larval supply of summer-recruiting reef fishes to Lee Stocking Island, Bahamas. Mar Ecol Prog Ser 112:75-86

Tolimieri N, Sale PF, Nemeth RS, Gestring KB (1998) Replenishment of populations of Caribbean reef fishes: are spatial patterns of recruitment consistent through time? J Exp Mar Biol Ecol 230:55-71

Underwood AJ, Denley EJ (1984) Paradigms, explanations, and generalizations in models for the structure of intertidal communities on rocky shores. In: Strong DR, Simberloff D, Abele LG, Thistl AB (eds) Ecological communities. Princeton University Press, Princeton, p 151-180

Utsunomi F (1965) Thoracica. In: Okada K, Uchida S, Uchida $\mathrm{R}$ (eds) New illustrated encyclopedia of the fauna of Japan. Hokuryu-kan, Tokyo, p 507-516

Victor BC (1986) Larval settlement and juvenile mortality in a recruitment-limited coral reef fish population. Ecol Monogr 56:145-160

Wing SR, Botsford LW, Morgan LE (1995) Spatial structure of relaxation events and crab settlement in the northern California upwelling system Mar Ecol Prog Ser 128:199-211

Wootton JT (1993) Size-dependent competition: effects on the dynamics vs. the end point of mussel bed succession. Ecology 74:195-206

Yoshioka PM (1982) Role of planktonic and benthic factors in the population dynamics of the bryozoan Membranipora membranacea. Ecology 63:457-468

Submitted: February 2, 2004; Accepted: June 3, 2004

Proofs received from author(s): August 12, 2004 